\title{
水酸アパタイトージルコニア系複合体のち密化及び機械的性質に 対するフッ化カルシウムの添加効果
}

\author{
玉利信幸・近藤 功・毛利元 哉* ·下下実 \\ $\left(\begin{array}{c}\text { 大阪工業技術試験所, } 563 \text { 池田市緑ケ丘 1-8-31 } \\ * \text { 武田薬品工業 (株), } 532 \text { 大阪市淀川区十三本町 2-17-85 }\end{array}\right)$
}

\section{Effect of Calcium Fluoride Addition on Densification and Mechanical Properties of Hydroxyapatite-Zirconia Composite Ceramics}

\author{
Nobuyuki TAMARI, Isao KONDO, Motoya MOURI* and Makoto KINOSHITA \\ ( Government Industrial Research Institute, Osaka, 8-31, Midorigaoka 1-chome, Ikeda-shi 563 ) \\ * Takeda Chemical Industries Ltd., 17-85, Jyuso-honmachi, Yodogawa-ku, Osaka-shi 532 )
}

\begin{abstract}
$\mathrm{CaF}_{2}$ up to 2.5 wt\% was added to a mixture of 50 vol\% hydroxyapatite (HAp) and 50 vol\% zirconia containing 2 mol\% $\mathrm{Y}_{2} \mathrm{O}_{3}$. The mixture was hot-pressed at $1300^{\circ}-1400^{\circ} \mathrm{C}$ and $20 \mathrm{MPa}$ for $10 \mathrm{~min}$. The sintered bodies obtained consisited of apatite (HAp and/or FAp) and zirconia (tetragonal and cubic phase). The addition of $\mathrm{CaF}_{2}$ enhanced the densification, incresing the bending strength and hardness. The bending strength of sintered body containing 0.5 wt\% CaF obtained at $1400^{\circ} \mathrm{C}$ was about $450 \mathrm{MPa}$, whose value was about $12 \%$ larger than that without $\mathrm{CaF}_{2}$. On the other hand, the fracture toughness was not improved by the addition of $\mathrm{CaF}_{2}$. After soaking in distilled water, saline and Ringer's solution, bending strength of the composite ceramics was 12-14\% lower than that in air. [Received March 14, 1988; Accepted August 17, 1988]
\end{abstract}

Key-words: Hydroxyapatite, Zirconia, Composite ceramics, Calcium fluoride, Densification, Mechanical properties

\section{1. 緒 言}

水酸アパタイト (以下 HAp と略記) やリン酸三カル シウムなどのリン酸カルシウム系焼結体は, 生体適合性 に優れているため人工骨や人工歯根等のインプラント材 料として注目されている ${ }^{1) \sim 4)}$. しかしながら，これら単 体ではインプラント材料としての実用化に対して十分な 強度, 勒性を持ち得ていない。 そこで, 著者らはこれら のリン酸カルシウム系焼結体の強度, 靶性の改善を目的 に種々のセラミック材料との複合化を検討してきた. そ の結果, HAp にジルコニアを $50 \mathrm{vol} \%$ 添加し, $1400^{\circ} \mathrm{C}$ で焼成して得られた複合セラミックスは, HAp 単体に 比べて強度, 靱性が 2 ないし 3 倍向上することを見いだ した ${ }^{5)}$. しかし，この複合セラミックスは $1400^{\circ} \mathrm{C}$ の焼 結温度でも $96 \%$ 程度の密度しか得られなかった。一方, $\mathrm{HAp}$ を焼結する際にフッ化カルシウム (以下 $\mathrm{CaF}_{2}$ と 略記）を少量添加することにより, HAp のち密化温度 を下げることができ, 強度, 勒性もやや向上することが 認められている6.

本研究では, HAp とジルコニアの混合物を焼結する 際に $\mathrm{CaF}_{2}$ を添加し, 得られた複合セラミックスのち密 化及び機械的性質に対する $\mathrm{CaF}_{2}$ の添加効果を調べた. また, これらの複合セラミックスの蒸留水中, 生理食塩 水中やリンゲル液中での強度も測定した。

\section{2. 実験方法}

HAp 粉末は, 湿式法により合成されたセントラル硝 子製の AN グレードのものを用いた。この粉末は, $\mathrm{Ca} / \mathrm{P}$ 比が 1.67 の化学量論組成を持ち, その 1 次粒子 の大きさは数百 $\AA$ である. ジルコニア粉末は, 東ソ一 製の TZ-2 $\mathrm{Y}\left(\mathrm{Y}_{2} \mathrm{O}_{3}\right.$ 含有量 $\left.2 \mathrm{~mol} \%\right)$ を用いた。 その平 均粒径は $0.3 \mu \mathrm{m}$ である. $\mathrm{CaF}_{2}$ 粉末としては, キシダ 化学製の試薬特級を使用した.

$50 \mathrm{vol} \% \mathrm{HAp}$ 亡 $50 \mathrm{vol} \%$ ジルコニアの混合物 $100 \mathrm{~g}$ に対して $\mathrm{CaF}_{2}$ を $0.25,0.5,0.87,1.5$, 及び $2.5 \mathrm{~g}$ 添 加した。焼結は, $1300^{\circ}, 1350^{\circ}$ 及び $1400^{\circ} \mathrm{C}, 10$ 分, 20 $\mathrm{MPa}$ の条件下, ホットプレスにより行った．粉末の処 理法及び焼結法は前報と同じである5). 得られた焼結体 は水中浸せき法によりかさ密度を測定した。

強度試験は，\#800 のダイヤモンド研磨板で引張り面 を仕上げた $3 \times 4 \mathrm{~mm}$ 角の試験片を用い, スパン $20 \mathrm{~mm}$, 荷重速度 $0.5 \mathrm{~mm}$ /分の条件下, 3 点曲げにより行った。 また, 蒸留水中, 生理食塩水中及びリンゲル液中での測 定ではそれぞれの液に 15 間分浸した後そのまま各液中 で試験を行った。靱性は, $1 \mu \mathrm{m}$ のダイヤモンドペース トで鏡面仕上げした後， $49 \mathrm{~N}, 30$ 秒の条件下, IF 法に より測定し，新原の式を用いてその值を求めた ${ }^{7)}$.また, 硬度は䩚性測定の際にビッカース硬度を求めた。 


\section{3. 結果と考察}

図 1 に, HAp-ジルコニア系複合体の相対密度に対す る各焼結温度における $\mathrm{CaF}_{2}$ の添加量の影響を示す。こ こでの相対密度の值は, HAp, ジルコニア (TZ-2 Y) 及び $\mathrm{CaF}_{2}$ が単純混合しているとして求めた理論密度に 対するかさ密度の比を表わしている. HAp，ジルコニ ア (TZ-2 Y) 及び $\mathrm{CaF}_{2}$ の理論密度はそれぞれ 3.16 $\mathrm{g} / \mathrm{cm}^{3}, 6.07 \mathrm{~g} / \mathrm{cm}^{3}$ 及び $3.18 \mathrm{~g} / \mathrm{cm}^{3}$ である.X 線回折に よると本複合体中のジルコニア相としてはいずれの $\mathrm{CaF}_{2}$ 添加量でも正方晶ジルコニアと立方晶ジルコニア が認められた．また， $\mathrm{CaF}_{2}$ を添加した際の焼結中にお いては次のような反応が起こっていると考えられる.

$$
\begin{aligned}
& \mathrm{Ca}_{10}\left(\mathrm{PO}_{4}\right)_{6}(\mathrm{OH})_{2}+\mathrm{CaF}_{2} \\
& \quad \rightarrow \mathrm{Ca}_{10}\left(\mathrm{PO}_{4}\right)_{6} \mathrm{~F}_{2}+\mathrm{CaO}+\mathrm{H}_{2} \mathrm{O} \\
& \mathrm{ZrO}_{2} \text { (正方晶) }[+\mathrm{CaO}] \rightarrow \mathrm{ZrO}_{2} \text { (立方晶) }
\end{aligned}
$$

$\mathrm{HAp}$ とフッ素アパタイト (FAp) は同じ結晶系で格子 定数も近いため, $1.5 \mathrm{wt} \%$ 添加の範囲では $\mathrm{X}$ 線回折で は HAp とFAp の区別が困難であったが, $2.5 \mathrm{wt} \%$ 添加 の時は HAp はほとんど FAp へ変化していることが認 められた. したがって, $1.5 \mathrm{wt} \%$ までの添加の際も $\mathrm{CaF}_{2}$ を添加した複合体中には $\mathrm{HAp}$ と $\mathrm{FAp}$ が共存して いると推察される，ところで，図1に示すようにいずれ の焼結温度においても本複合体のち密化に対して $\mathrm{CaF}_{2}$ の添加効果か認められ, 添加量の増加とともに相対密度 は大きくなり, $1 \mathrm{wt} \%$ 前後で最大になった. $2.5 \mathrm{wt} \%$ 添加した場合は若干低下する傾向にあった，各焼結温度 での最大密度は, $1300^{\circ} \mathrm{C}$ で $94 \%, 1350^{\circ} \mathrm{C}$ で $98.5 \%$, $1400^{\circ} \mathrm{C}$ で $99.5 \%$ であった.

図 2 に, $1400^{\circ} \mathrm{C}$ で焼結した複合体の曲げ強度に対す る $\mathrm{CaF}_{2}$ 添加量の影響を示す. 曲げ強度は, 無添加のと きは約 $400 \mathrm{MPa}$ であったが, 添加量の増加に伴う密度 の増大に従って大きくなり，0.5 wt\% 添加で最大值 450

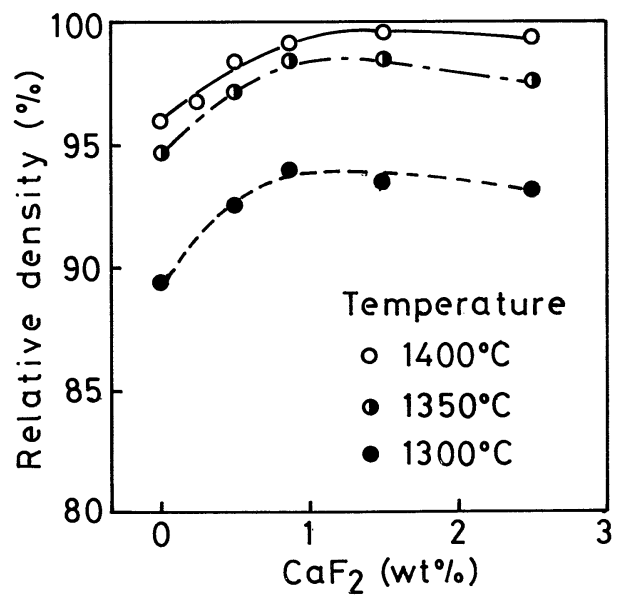

Fig. 1. Effect of $\mathrm{CaF}_{2}$ addition on the relative densities of $\mathrm{HAp}-\mathrm{ZrO}_{2}$ composite ceramics.

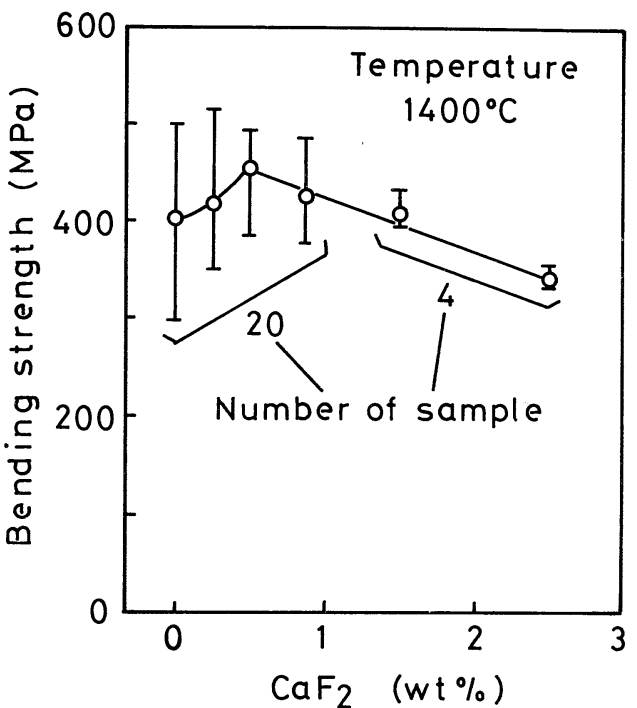

Fig. 2. Effect of $\mathrm{CaF}_{2}$ addition on the bending strengths of $\mathrm{HAp}-\mathrm{ZrO}_{2}$ composite ceramics sintered at $1400^{\circ} \mathrm{C}$.

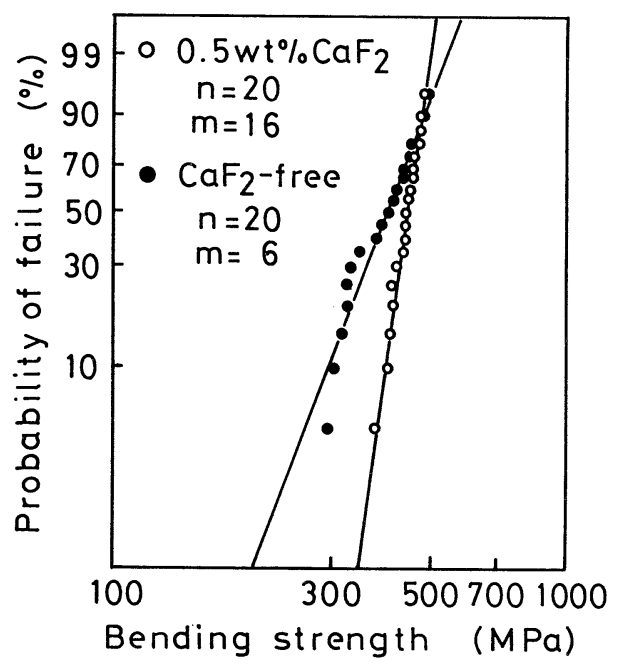

Fig. 3. Weibull's distribution for the bending strengths of $\mathrm{HAp}-\mathrm{ZrO}_{2}$ composite ceramics without $\mathrm{CaF}_{2}$ and added with $0.5 \mathrm{wt} \% \mathrm{CaF}_{2}$ sintered at $1400^{\circ} \mathrm{C}$.

$\mathrm{MPa}$ になった。 しかし，これ以上添加量を増やしてい くとかえって強度は低下し, $2.5 \mathrm{wt} \%$ 添加では無添加 のときより低い強度值しか得られなかった．また， $\mathrm{CaF}_{2}$ 添加による密度の改善の結果, 本複合体の強度の ばらつきが小さくなる傾向も認められた. 図 3 に, $1400^{\circ} \mathrm{C}$ 焼結体の $\mathrm{CaF}_{2}$ 無添加の場合亡最大の強度值が 得られた $0.5 \mathrm{wt} \%$ 添加の場合の各 20 本の試験片につい てのワイブル分布の比較を行った結果を示す．無添加の 場合のワイブル係数は約 6 であったが, $0.5 \mathrm{wt} \%$ 添加 の場合は約 16 になった。 
Table 1. Bending stregths of $\mathrm{HAp}-\mathrm{ZrO}_{2}$ composite ceramics without $\mathrm{CaF}_{2}$ and added with $0.5 \mathrm{wt} \% \mathrm{CaF}_{2}$, measuring in air, in distilled water, in saline and in Ringer's solution.

\begin{tabular}{|c|c|c|}
\hline \multirow[t]{2}{*}{ Atmosphere } & \multicolumn{2}{|c|}{$\begin{array}{l}\text { Bending strength (MPa) } \\
\text { (Number of sample) }\end{array}$} \\
\hline & $\mathrm{CaF}_{2}$-free & $0.5 \mathrm{wtz}_{\mathrm{z}} \mathrm{CaF}_{2}$ \\
\hline in air & $\begin{array}{c}403 \pm 69 \\
(20)\end{array}$ & $\begin{array}{l}451 \pm 30 \\
(20)\end{array}$ \\
\hline $\begin{array}{l}\text { in distilled } \\
\text { water }\end{array}$ & $\begin{array}{c}351 \pm 51 \\
(8) \\
\end{array}$ & $\begin{array}{c}400 \pm 40 \\
(10)\end{array}$ \\
\hline $\begin{array}{l}\text { in saline } \\
\text { solution }\end{array}$ & $\begin{array}{c}358 \pm 39 \\
(8)\end{array}$ & $\begin{array}{l}389 \pm 42 \\
(10)\end{array}$ \\
\hline $\begin{array}{l}\text { in Ringer's } \\
\text { solution }\end{array}$ & $\begin{array}{c}347 \pm 55 \\
(8)\end{array}$ & $\begin{array}{c}387 \pm 39 \\
(10)\end{array}$ \\
\hline
\end{tabular}

表 1 に, $\mathrm{CaF}_{2}$ 無添加の場合と $0.5 \mathrm{wt} \%$ 添加した場合 の各種雲囲気中 (空気中, 蒸留水中, 生理食塩水中, 及 びリンゲル液中）での強度測定を行った結果を示す．本 複合体は, $\mathrm{CaF}_{2}$ の添加に関係なく空気中に比べて蒸留 水中, 生理食塩水中及びリンゲル液中では強度低下が見 られた。その低下割合は $\mathrm{CaF}_{2}$ 無添加及び $0.5 \mathrm{wt} \%$ 添 加の場合ともほぼ同程度で, また, 蒸留水中, 生理食塩 水中及びリンゲル液中の間においてほとんど差異は見ら れず，空気中の 86〜88\%であった．同様な現象がアル ミナの強度測定でも認められており, その際の低下割合 は $10 \%$ 程度であった 8 . 上記に示したように蒸留水中,

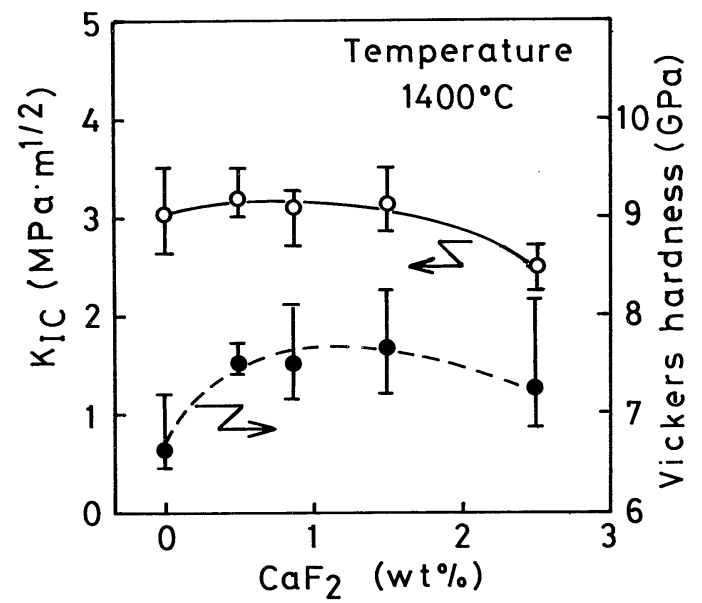

Fig. 4. Effect of $\mathrm{CaF}_{2}$ addition on the fracture toughness and Vickers hardness of $\mathrm{HAp}-\mathrm{ZrO}_{2}$ composite ceramics sintered at $1400^{\circ} \mathrm{C}$.
生理食塩水中, 及びリンゲル液中の测定でほぼ同程度の 強度低下を示したことより，この強度低下の一因として 水の影響が大きいと考えられる. 一般に水の存在下でセ ラミッススに応力を掛けると次のような化学反応が促進 され,

$$
\begin{aligned}
& -\mathrm{M}-\mathrm{O}-\mathrm{M}-+\mathrm{H}_{2} \mathrm{O} \\
& \quad \rightarrow-\mathrm{M}-\mathrm{OH}+\mathrm{HO}-\mathrm{M}-
\end{aligned}
$$

クラックが進展するか, もしくはクラックの先端が鋭角 化され, 低強度で破壊する ${ }^{9)}$. 本複合体の場合にも上式 のような反応が生じて蒸留水中, 生理食塩水中及びリン ゲル液中では強度低下を招いたと考えている.

図 4 に, 図 2 と同じ試料の破壊靶性及び硬度の测定結 果を示す. 破壊勒性は $\mathrm{CaF}_{2}$ 添加量 $1.5 \mathrm{wt} \%$ までの範 囲では無添加のときと同じく約 $3.0 \mathrm{MPa} \cdot \mathrm{m}^{1 / 2}$ の值で あったが, $2.5 \mathrm{wt} \%$ 添加では強度と同様に無添加のと きの值より小さくなった。このように $\mathrm{CaF}_{2}$ の添加量が 多くなると強度, 鞀性が低くなる原因として, （1）式 及び ( 2 ) 式の反応が起こる結果, 得られた複合体中の 正方晶ジルコニアの割合が小さくなることが考えられ る. 実際, $\mathrm{X}$ 線解析によると $\mathrm{CaF}_{2}$ 添加量が多くなるに 従い, 正方晶ジルコニアに対する立方晶ジルコニアの割 合, すなわち, $I(400)_{\mathrm{c}} /\left[I(400)_{\mathrm{T}}+I(004)_{\mathrm{T}}\right]$ の比が大 きくなり，0.87 wt\% までの範囲では 0.30 程度で, 1.5 wt\% では $0.44,2.5 \mathrm{wt} \%$ では 0.60 であった. 一方, 硬度は $\mathrm{CaF}_{2}$ の添加によりち密化が進んだため無添加の 值（約 $6.6 \mathrm{GPa}$ ) より大きくなり，1.5 wt\% 添加では 約 $7.6 \mathrm{GPa}$ になった.

\section{文献}

1）加藤一男, 青木秀希, セラミックス，15，418-26 (1980).

2) S. F. Hulbert, L. L. Hench, D. Forbers and L. S. Bowman, Ceram. Inter., 8, 131-40 (1982).

3）作花済夫，小久保 正，セラミックス，17，342-47 (1982).

4) 青木秀希, 工業材料, 31, 201-06 (1983).

5）玉利信幸, 毛利元哉, 近藤 功, 窯協, 95, 806-09 (1987).

6）玉利信幸, 近藤 功, 木下 実, 粉体および粉末冶金, 34, 91-94 (1987).

7）“ファインセラミックスの標準化に関する調査報告書”, ファインセラミックス協会 (1984) p. 74 .

8) B. J. Dalgleish and R. D. Rawlings, J. Biomed. Mater. Res., 15, 527-42 (1981).

9）伊藤節朗, 機械の研究, 40, 145-150 (1988). 